\title{
Expression of transcription factor NF-KAPPA B/P65 and cyclooxygenase-2 (COX-2) in testicular damage induced by Red Bull energy drink in rat
}

\author{
Aly Mohamed Ahmed * \\ Department of Anatomy, College of Medicine, King Saud University, Riyadh, Saudi Arabia
}

\section{ARTICLE INFO}

Article history:

Received 22 June 2016

Received in revised form

13 October 2016

Accepted 15 October 2016

\section{Keywords:}

Red Bull

Testis

NF-kB/p65

COX-2

\begin{abstract}
A B S T R A C T
The risks of heavy consumption of energy drinks have become a significant health problem. Concerns have been raised about the adverse health effects of these products. This study was performed to investigate the possible histopathological and immunohistochemical changes in the testis induced by excessive and prolonged consumption of Red Bull, one of the most consumed energy drinks all over the world, in rats and the possible mechanism of such changes. Thirty adult male albino rats were randomly allocated into two groups, each of 15 animals. Rats of control group received distilled water $(1.071 \mathrm{ml} / 100 \mathrm{~g} /$ day $)$ for three months. Rats of Red Bull group received an equivalent dose of Red Bull for three months. At the end of the experiment, all animals were sacrificed under anesthesia and the testes were excised and processed for histopathological and immunohistochemical studies. Consumption of Red Bull energy drink caused extensive atrophy and damage of numerous seminiferous tubules with marked loss of germinal epithelial cells and marked interstitial edema. Immunostaining results demonstrated marked increase of NF-kB/p65 and COX-2 in testis of rats following consumption of Red Bull energy drink. The results of this study suggest that excessive and prolonged consumption of Red Bull energy drink induces extensive histopathological lesions in the testis of rats through upregulation of NF-kB/p65 and COX-2.
\end{abstract}

(C) 2016 The Authors. Published by IASE. This is an open access article under the CC BY-NC-ND license (http://creativecommons.org/licenses/by-nc-nd/4.0/).

\section{Introduction}

Energy drinks were first introduced in Europe in 1987 and in USA in 1997 (Zucconi et al., 2013). They are now available in more than 140 countries (Zucconi et al., 2013). One of the most popular energy drinks in USA is Red Bull (Ali et al., 2015), a non-alcoholic drink that contains caffeine (usually its main ingredient), taurine, B vitamins, guarana, ginseng, and glucuronolactone (Higgins et al., 2010). Doses of these ingredients often exceed recommended dietary intake levels (Tanne, 2012). Caffeine doses, for example, range from 50 to $505 \mathrm{mg}$ per serving (Burrows et al., 2013).

In fact, the risks of heavy consumption of energy drinks, particularly among adolescents and young people, have largely gone unaddressed and became a significant health problem (Breda et al., 2014). Despite this, there have been limited studies carried

\footnotetext{
* Corresponding Author.

Email Address: alymahmed53@gmail.com

https://doi.org/10.21833/ijaas.2016.10.009

2313-626X/C 2016 The Authors. Published by IASE.

This is an open access article under the CC BY-NC-ND license

(http://creativecommons.org/licenses/by-nc-nd/4.0/)
}

out on the risks associated with the increase in energy drink consumption (Zeidán-Chuliá et al., 2013; Breda et al., 2014). On the other hand, marketing of energy drinks focuses on their stimulant effects and perceived benefits such as increased physical performance, attention, stamina, and weight loss, which remain unproven (Reissig et al., 2009). Therefore, further studies are required to examine the potential adverse health effects of longterm, habitual consumption of energy drinks (Zeidán-Chuliá et al., 2013).

To the best of the author's knowledge, there are no previous studies on the histopathological and immunohistochemical changes in the testis following consumption of Red Bull energy drink. Hence, the present study was performed to investigate the possible histopathological and immunohistochemical effects on the testis following excessive and prolonged consumption of Red Bull energy drink and to evaluate the modulating roles of $\mathrm{NF}-\mathrm{kB} / \mathrm{p} 65$ activation and COX-2 expression in the pathogenesis of the induced oxidative stress testicular damage.

\section{Material and methods}

\subsection{Experimental animals}


Thirty adult male Wistar albino rats, with a body weight (BW) between 150-200 g, were supplied by the Animal Care Center at the College of Medicine, King Saud University, Riyadh, Kingdom of Saudi Arabia. Rats were housed and maintained under standard controlled environmental conditions in individual metallic cages at a controlled temperature of $25 \pm 2{ }^{\circ} \mathrm{C}$ with a fixed 12-hour light/dark cycle throughout the study with free access to standard pelleted rat chow and tap water ad libitum. The animals were acclimatized for a period of one week before the start of the experiment. All the experimental procedures were conducted in accordance with the research ethics standards established by the Guidelines for the Care and Use of Laboratory Animals of the College of Medicine Research Center (CMRC) at King Saud University and conform to the Guide for the Care and Use of Laboratory Animals published by the National Institutes of Health (NIH), USA.

\subsection{Chemicals}

The primary antibodies used were a mouse monoclonal transcription factor NF-kappa B/p65 (NF-kB/p65) antibody and a goat polyclonal cyclooxygenase-2 (COX-2) antibody. These primary antibodies were purchased from Santa Cruz Biotechnology, Inc. (Dallas, Texas, USA).

\subsection{Experimental designs}

Thirty rats were randomly allocated into 2 groups of 15 rats each:

Group I (control group): Rats were givendistilled water with a daily dose of $1.071 \mathrm{ml} / 100 \mathrm{~g}$ body weight for three months, using oropharyngeal metallic curved tube. Rats of Red Bull group received an equivalent dose of Red Bull for three months.

Group II (RedBullgroup): Rats were given Red Bullwith a daily dose of $1.071 \mathrm{ml} / 100 \mathrm{~g}$ body weight for three months, using oropharyngeal metallic curved tube(Ferreira et al., 2004).

Each can of Red Bull (Red Bull; Taurine drink, filled in Switzerland by Rauch Trading AG for Red Bull GmbH, Austria) contains $250 \mathrm{ml}$ of fluid. Ingredients include water, glucose, sucrose, sodium citrate, carbon dioxide, taurine $(0.4 \%)$, caffeine $(0.03 \%)$, glucuronolactone $(0.24 \%)$, inositol $(0.02 \%$ ), B vitamins (B3, B5, B6, B12), and flavors.

At the end of the experiment, all animals were sacrificed under anesthesia with pentobarbital sodium $(60 \mathrm{mg} / \mathrm{kg}$, intraperitoneally) (Zhao et al., 2013). The testes were immediately excised, fixed in $10 \%$ buffered formalin, and processed forhistopathological and immunohistochemical studies.

\subsection{Histopathological study}

The excised testes were fixed in $10 \%$ buffered formalin at $4^{\circ} \mathrm{C}$ for 24 hours and processed to prepare transverse, 5 - $\mu$ m-thick paraffin sections. These sections were stained with hematoxylin and eosin (H\&E) (Stevens and Wilson, 1999) and periodic acid-Schiff (PAS) (Cormack, 1999).

\subsection{Immunohistochemical study}

Immunostaining of sections of the testis for detection of NF-kB/p65 and COX-2 were performed using streptavidin-biotinylated horse radish peroxidase method (Novalink Max Polymer detection system; Novocastra Laboratories, Newcastle, UK). The procedure involved the following steps: endogenous peroxidase activity was inhibited by $3 \% \mathrm{H}_{2} \mathrm{O}_{2}$ in distilled water for 5 minutes and then the sections were washed in Tris-buffered saline (TBS,pH 7.6) (Sigma-Aldrich) for10 minutes. Non-specific binding to antibodies was blocked by incubation with protein block for 5 minutes (Novocastra). Sections were incubated with an antibody against NF-kB/p65 (1:100dilution, Santa Cruz, TX, USA) and an antibody against COX-2 (1:100dilution, Santa Cruz, TX, USA) according to the manufacturer's instructions. Sections were washed 3 times in TBS, each for 3 minutes, and then incubated with biotinylated IgG (Novocastra) for 30 minutes, followed by washing in TBS and incubation with Novolink polymer (Novocastra) for 30 minutes. Sections were washed in TBS for 3 times, each for 3 minutes. Peroxidase was detected with working solution of diaminobenzedine (DAB) substrate (Novocastra) for 10 minutes. Sections were washed in distilled water for 10 minutes, nuclei were stained with Mayer's hematoxylin and sections were mounted in DPX (Dysterene, Plasticizer, Xylene). For negative control sections, the same procedure was followed but with omission of incubation in the primary antibodies.

\subsection{Image analysis}

High-resolution whole-slide digital scans of all stained sections were created with a ScanScope scanner (Aperio Technologies, Inc.). The digital slide images were then viewed and analyzed using the viewing and image analysis tools of Aperio's ImageScope software (Aperio Technologies, Inc.). To quantify the immunopositive reaction, five areas, each with the fixed size of $0.264 \mathrm{~mm}^{2}$, were randomly selected per section, and the color deconvolution (color separation) algorithm (Aperio Technologies, Inc.) was set up (by color calibration) to detect and quantify only the brown color of DAB positive immunostaining. The algorithm was then run on the selected areas to measure the percentage of the color of interest relative to the total area of analysis. All image analysis output results were finally exported to Excel sheets and subjected to statistical analysis.

\subsection{Statistical analysis}


Data collected were subjected to statistical analysis using IBM SPSS Statistics version 22 software. Student's t-test was used for comparison between the groups. Differences were considered significant when $p$ value was less than or equal to 0.05 .

\section{Results}

\subsection{Histopathology}
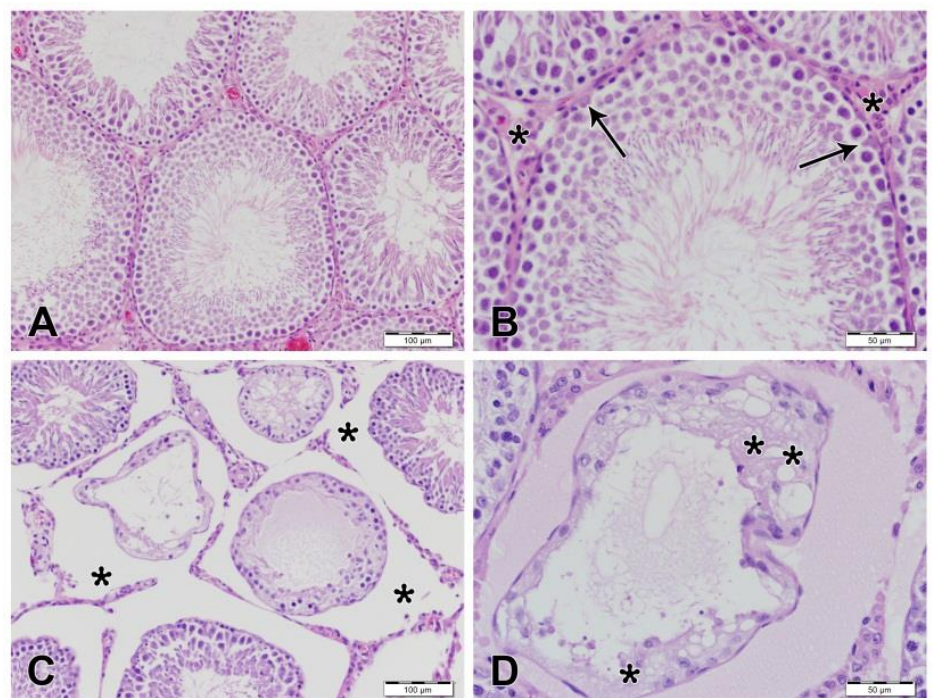

Fig. 1: H\&E-stained sections of the testis. (A) From control rat showing normal architecture of seminiferous tubules and interstitial tissue. Scale bar $=100 \mu \mathrm{m}$. (B) Higher magnification of control testis showing germinal epithelial cells, Sertoli cells

(arrows), and interstitial cells (asterisks). Scale bar $=50 \mu \mathrm{m}$. (C) From Red Bull treated rat showing massive damage of several seminiferous tubules with marked interstitial edema (asterisks).Scale bar $=100 \mu \mathrm{m}$. (D) Higher magnification of " $\mathrm{C}$ " showing marked loss of germinal epithelium (asterisks). Scale bar $=50 \mu \mathrm{m}$.

Periodic acid Schiff (PAS)-stained sections of the testis from control rats showed PAS-positive reaction in the basement membrane of seminiferous tubules and the acrosomal cap of spermatids and spermatozoa (Fig. 2 A, B). However, PAS-stained sections from Red Bull-treated rats showed depletion of PAS-positive reaction in basement membrane of seminiferous tubules with almost complete absence of acrosomal cap (Fig. 2 C, D).
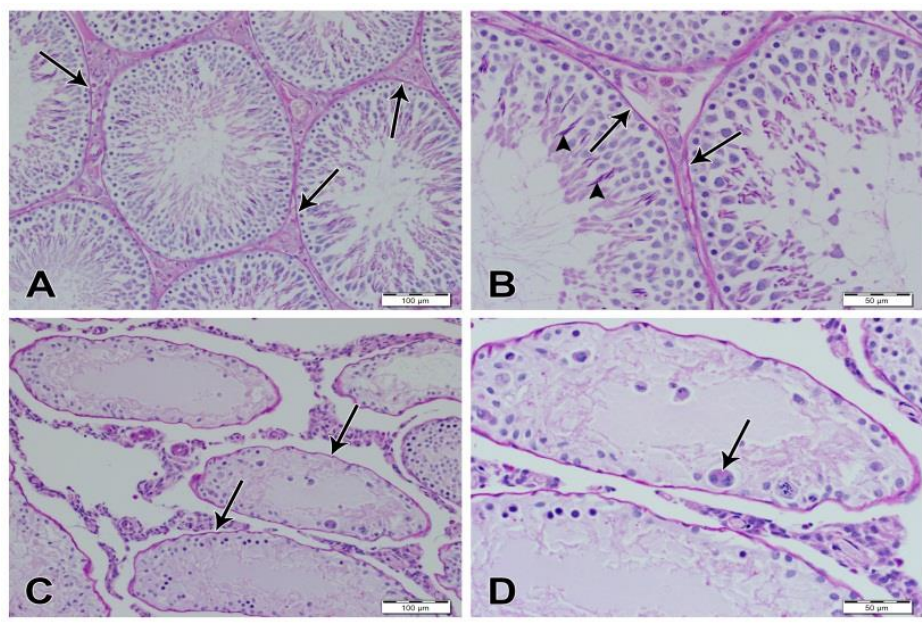

Fig. 2: PAS-stained sections of the testis. (A) From control rat showing PAS-positive reaction in the basement membrane of seminiferous tubules (arrows). Scale bar $=100 \mu \mathrm{m}$. (B) Higher magnification of control testis showing PAS-positive basement membranes of seminiferous tubules (arrows) and acrosomal caps (arrowheads). Scale bar $=50 \mu \mathrm{m}$. (C) From Red Bull treated rat showing marked depletion of PAS-positive reaction in basement membranes of seminiferous tubules (arrows). Scale bar = $100 \mu \mathrm{m}$. (D) Higher magnification of "C" showing a multinucleated giant cell (arrow).Scale bar $=50 \mu \mathrm{m}$. 


\subsection{Immunohistochemistry}

Immunostaining of sections of the testis from Red Bull-treated rats showed marked increase in the expression of $\mathrm{NF}-\mathrm{kB} / \mathrm{p} 65$ and $\mathrm{COX}-2$ compared to the controls.

Immunostaining of sections of the testis from control rats showed moderate immunoexpression of
NF-kB/p65 in cytosol of most of the cells of seminiferous tubules and the interstitial tissue cells (Fig. 3 A, B). However, following Red Bull consumption, this immunoexpression was markedly increased in both cytosol and most nuclei of these cells (Fig. 3 C, D).

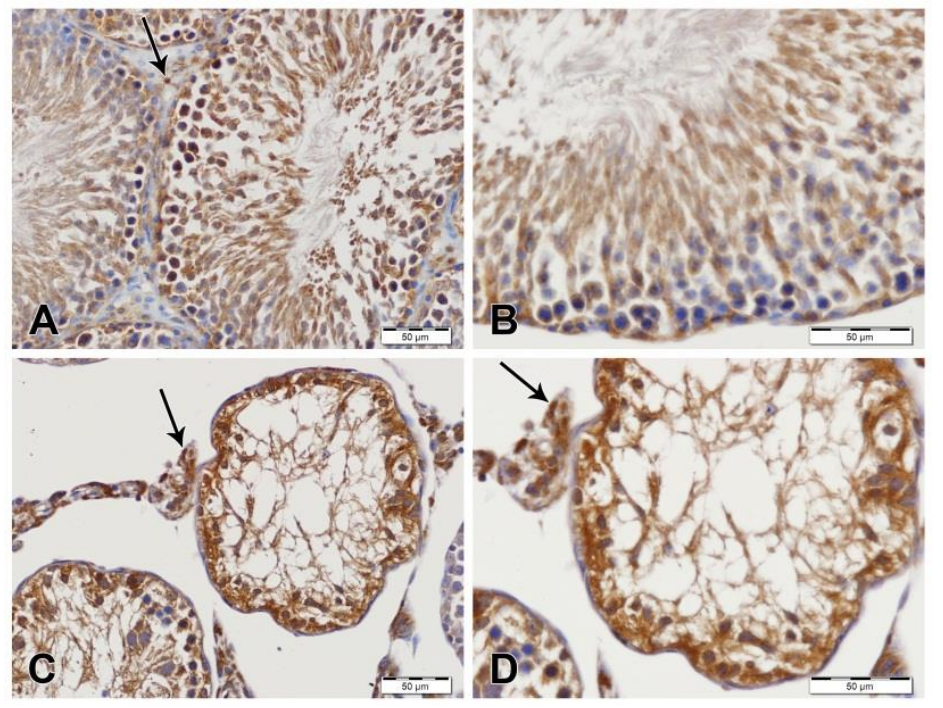

Fig. 3: NF-kB/p65 immunostained sections of the testis. (A) From control rat showing moderate immunostaining of all cells of seminiferous tubules and interstitial cells (arrow). (B) Higher magnification of control testis showing moderate immunostaining of cytosol of cells of seminiferous tubules. (C) From Red Bull treated rat showing strong immunostaining in cytosol and most of nuclei of cells of seminiferous tubules and interstitial cells (arrow). (D) Higher magnification of "C" showing strong immunostaining in cytosol and most of nuclei of cells of seminiferous tubules and interstitial cells (arrow).Scale bars $=50 \mu \mathrm{m}$

Immunostaining of sections of the testis from control rats showed almost complete imunonegativity of COX-2 (Fig. 4 A, B). However, following Red Bull consumption, COX-2 immunoexpression was strongly positive in cytosol of interstitial cells (Fig. 4 C, D).

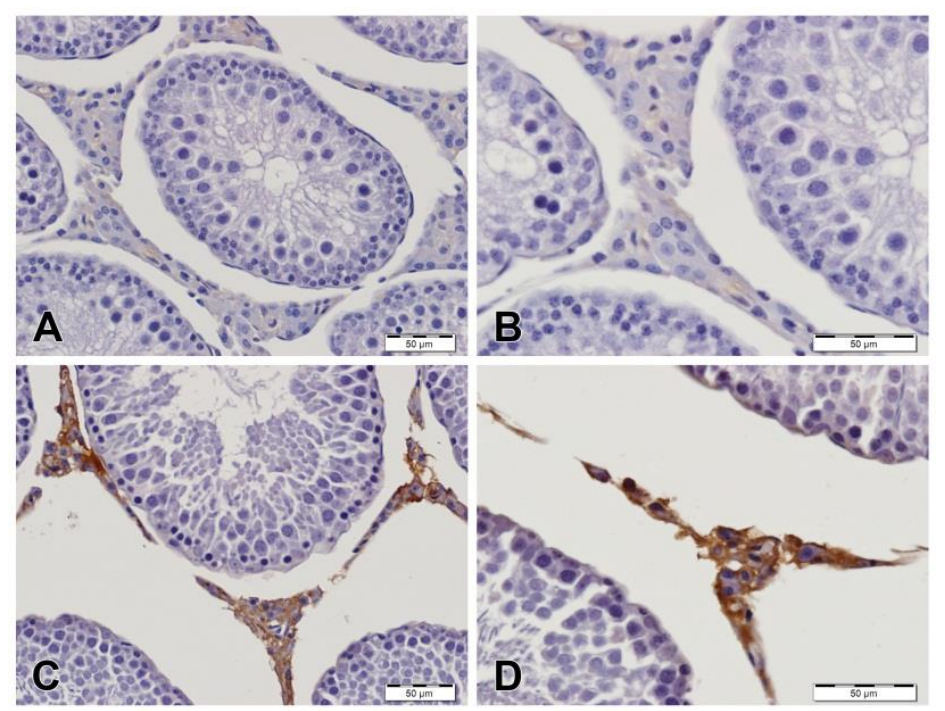

Fig. 4: COX-2 immunostained sections of the testis. (A) From control rat showing almost complete negative immunostaining of all types of cells. (B) Higher magnification of control testis showing almost complete negative immunostaining of all types of cells. (C) From Red Bull treated rat showing strong immunostaining in cytosol of almost all interstitial cells. (D) Higher magnification of " $\mathrm{C}$ " showing strong immunostainingin cytosol of almost all interstitial cells.Scale bars $=50 \mu \mathrm{m}$.

\section{Discussion}

The present study showed that excessive and prolonged consumption of Red Bull energy drink induced severe histopathological changes in the testis of male adult rat. A cross-sectional survey reported that almost one third of energy drink 
consumers experienced some type of energy drinkrelated adverse events (Nordt et al., 2012).

Previous studies demonstrated histopathological lesions in different organs following administration of energy drinks. These organs include testis (Dias et al., 2015), pancreas, fundus of stomach (Ayuob and ElBeshbeishy, 2016), and liver (Khayyat et al., 2012).

These lesions could be attributed to imbalance of oxidant/antioxidant environment in these tissues with increased oxidant stress as a result of the production of inducible nitric oxide synthase (iNOS) and tumor necrosis factor-alpha (TNF- $\alpha$ ) (Ayuob and ElBeshbeishy, 2016). These mechanisms are triggered as a result of high content of caffeine in energy drinks (Ayuob and ElBeshbeishy, 2016).

Caffeine is by far the main active ingredient in energy drinks, and consumption in large amounts causes the effects of caffeine intoxication (Wolk et al., 2012). High caffeine doses, repeated dosing, and habitual caffeine intake generally result in prolongation of its half-life and reduced clearance of caffeine and its metabolite, increasing the potential for caffeine toxicity (Higgins and Babu, 2013). Ali et al. (2015) reported that a safe dose of caffeine is 200 to $300 \mathrm{mg}$, whereas many energy drinks have caffeine content in the $500 \mathrm{mg}$ range. Caffeine has been implicated in a number of epidemiologic studies as a risk factor for infertility (Wilcox et al., 1988).

An in vivo study with Sprague-Dawley rats demonstrated that an oral administration of an elevated dose of $200 \mathrm{mg} / \mathrm{kg}$ of body weight of caffeine negatively affects the histoarchitecture of the seminiferous tubules of the testes, with massive loss of spermatogenic cells and testicular weight loss (Bassey et al., 2011). Another study with the same dosage of caffeine also reported testicular weight loss as well as histological alterations including atrophic cells with necrosis and excessive degeneration of spermatids and almost absence of spermatozoa (Ekaluo et al., 2014). Breakdown of the germinal epithelium was reported in adult albino rats that received $30 \mathrm{mg} / \mathrm{kg} /$ day of caffeine given by gavage for 15-38 consecutive days (Pollard and Smallshaw, 1988).

Daily administration of 30 to $60 \mathrm{mg} / \mathrm{kg}$ of caffeine to mature male rabbits for four consecutive weeks caused a decrease in the sizes of seminiferous tubules and inhibited spermatogenesis (Ezzat and elGohary, 1994). Severe bilateral testicular atrophy with aspermiogenesis or oligospermatogenesis was observed in 85 to 100 percent of 4- to 6-week-old male rats fed caffeine for periods ranging from 14 to 75 weeks (Friedman et al., 1979).

Reactive oxygen species (ROS) are likely implicated in the pathogenesis of wide variety of human diseases. ROS are very reactive and may inflict direct damage to vital cell constituents such as lipids, proteins, and DNA. ROS are also involved in the regulation of gene expression (Sen and Packer, 1996). Oxidative stress is known to stimulate transcription factors, including nuclear factor-kappa B (NF-kB) (Bubici et al., 2006).
There is an increasing interest in the involvement of transcription factors, such as the transcription factor NF-kB, in the pathogenesis of various diseases by regulating the transcription of genes that control the inflammatory response by the production of cytokines and chemokines (van den Berg et al., 2001).

Also, NF-kB is known to activate many genes, including iNOS, resulting in excessive nitric oxide (NO) generation (Kleinert et al., 2004). Excessive production of NO due to elevated expression of iNOS causes vasodilatation leading to organ hypoperfusion, edema, and organ dysfunction. The contribution of NO to tissue damage can be a direct effect mediated by NO it (Davis et al., 2001). NO can interact with ROS to form peroxynitrite, which is a powerful oxidant and cytotoxic agent and may play an important role in the cellular damage associated with the overproduction of NO (Davis et al., 2001).

In quiescent cells, NF-kB is located in the cytosol as a dimer of protein compounds (p50/p65) bound to an inhibitor (IkB) in an active state (van den Berg et al., 2001). NF-kB enhances the expression of inflammatory genes ending for cytokines, such as interleukin-1 (IL-1), chemokines, growth factors, and cell adhesion molecules (van den Berg et al., 2001). In fact, NF-kB also regulates the expression of inflammatory enzymes, including the inducible form of nitric oxide synthase (iNOS) (Xie et al., 1994) and inducible cyclooxygenase (COX-2) (Crofford et al., 1997).

Cyclooxygenase-2 (COX-2), the inducible key enzyme for the prostaglandin (PG) biosynthetic pathway, is abundantly present in interstitial cells of tests of man suffering from different forms of impaired spermatogenesis and sub- or infertility, but it is absent in human testes with normal spermatogenesis (Frungieri et al., 2002). It has been found that adult golden hamster Leydig cells express active COX-2 linked to production of prostaglandin (PG) (Frungieri et al., 2006). This PG inhibits gonadotropin-stimulated testosterone production by altering steroidogenic enzymes (Schell et al., 2007).

It has been reported that in the human testes with impaired spermatogenesis, prostaglandins are likely to be produced by mast cells and Leydig cells. Significantly more and activated mast cells are found in testes of infertile men (Meineke et al., 2000).

Frungieri et al. (2007) have reported that whereas COX-2 is not detected in normal human testes; it is expressed in testicular biopsies of men with impaired spermatogenesis and male infertility. These authors have also reported that COX-2 expression is induced in rat Leydig cells during aging. Studies performed in rats have shown that COX-2 appears to play a role in the decrease of the testicular production of testosterone that takes place during aging (Wang et al., 2005).

It was reported that prostaglandins biosynthesis is initiated by the action of COX (Frungieri et al., 2007). Studies point out that the administration of PG produces a marked inhibition of spermatogenesis 
and a dramatic decrease in the number of sperms (Moskovitz et al., 1987).

\section{Clinical implications}

This study offers the possibility to use NF-kB measurement as a functional biomarker of oxidative stress in various pathologic conditions in addition to Red Bull energy drink heavy consumption. Also, regulation and reducing of NF-kB activation can be a powerful therapeutic strategy for reducing tissue damage or other complications induced by oxidative stress such as in heavy consumption of Red Bull energy drink. In addition, further advances in the knowledge of the role played by COX-2 and PG in reproductive physiopathology could lead to the development of new therapeutical approaches in male infertility induced by many pathological conditions (Fig. 5).

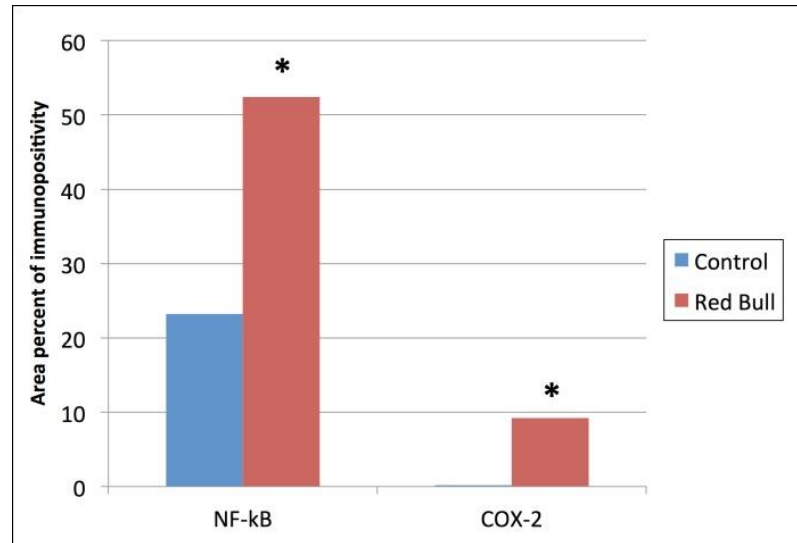

Fig. 5: Mean area percent of immunopositivity for NF-kB and COX-2 in the studied groups. ${ }^{*}$ Significant difference $(p$ $\leq 0.05$ ) versus control group

\section{Limitations of the study}

The present study did not investigate the longterm effects of exposure to different doses of Red Bull energy drink or its ingredients on the reproductive parameters and fertility in male rats. Also, the present study did not investigate whether the testicular histopathological lesions in Red Bull treated rats are reversible or not. In addition, the present study did not demonstrate the possible protective antioxidant agents to ameliorate or prevent the Red-Bull-induced testicular lesiosns.

\section{Conclusion}

In summary, this study suggests that excessive and prolonged consumption of Red Bull energy drink adversely damages the testicular tissue through increasing the expression of NF-kB/p65 and COX-2 in testis of rats.

\section{Acknowledgments}

The author gratefully acknowledges the Research Center, College of Medicine, Deanship of Scientific
Research, King Saud University, Riyadh, Kingdom of Saudi Arabia for the financial support and continuous encouragement.

\section{Conflict of interest, human and animal rights, and informed consent}

The author has declared no conflicts of interest exist. All the experimental procedures were conducted in accordance with the research ethics standards established by the Guidelines for the Care and Use of Laboratory Animals of the College of Medicine Research Center (CMRC) at King Saud University and conform to the Guide for the Care and Use of Laboratory Animals published by the National Institutes of Health (NIH), USA.

\section{References}

Ali F, Rehman H, Babayan Z, Stapleton D and Joshi DD (2015). Energy drinks and their adverse health effects: A systematic review of the current evidence. Postgraduate medicine, 127(3): 308322.

Ayuob N and ElBeshbeishy R (2016). Impact of an energy drink on the structure of stomach and pancreas of albino rat: Can omega- 3 provide a Protection? PLoS One, 11(2): e0149191. https://doi.org/10.1371/journal.pone.0149191

Bassey RB, Yama OE, Osinubi AA, Noronha CC and Okanlawon A (2011). Effects of Tahitian Noni dietary supplement on caffeine-induced testicular histo-pathological alterations in adult SpragueDawley rats. Middle East Fertility Society Journal, 16(1): 61-66.

Breda JJ, Whiting SH, Encarnação R, Norberg S, Jones R, Reinap M and Jewell J (2014). Energy drink consumption in europe: a review of the risks, adverse health effects, and policy options to respond. Frontiers in Public Health, 2: article no.134. doi.org/10.3389/fpubh.2014.00134

Bubici C, Papa S, Dean K and Franzoso G (2006). Mutual cross-talk between reactive oxygen species and nuclear factor-kappa B: molecular basis and biological significance. Oncogene, 25(51): 6731-6748.

Burrows T, Pursey K, Neve M and Stanwell P (2013). What are the health implications associated with the consumption of energy drinks? A systematic review. Nutrition reviews, 71(3): 135-148.

Cormack HC. (1999). Carbohydrates. In: Bancroft J and Stevens A (Eds.), Theory and Practice of Histological Techqniues. Churchill Livingstone, London, New York, Toronto: 173-212.

Crofford LJ, Tan B, McCarthy CJ and Hla T (1997). Involvement of nuclear factor kappa $B$ in the regulation of cyclooxygenase- 2 expression by interleukin-1 in rheumatoid synoviocytes. Arthritis \& Rheumatism, 40(2): 226-236. 
Davis KL, Martin E, Turko IV and Murad F (2001). Novel effects of nitric oxide. Annual Review of Pharmacology and Toxicology, 41(1): 203-236

Dias TR, Alves MG, Bernardino RL, Martins AD, Moreira AC, Silva J, Barros A, Sousa M, Silva BM and Oliveira PF (2015). Dose-dependent effects of caffeine in human Sertoli cells metabolism and oxidative profile: relevance for male fertility. Toxicology, 328: 12-20.

Ekaluo U, Ikpeme E, Etta S, Erem F and Daniel I (2014). Protective role of soursop (Annona muricata L.) fruit on testicular toxicity induced by caffeine in albino rats. Journal of Life Sciences Research and Discovery, 1: 26-30.

Ezzat AR and el-Gohary ZM (1994). Hormonal and histological effects of chronic caffeine administration on the pituitary-gonadal and pituitary-adrenocortical axes in male rabbits. Functional and Developmental Morphology, 4(1): 45-50.

Ferreira SE, Hartmann Quadros IM, Trindade AA, Takahashi S, Koyama RG and Souza-Formigoni MLO (2004). Can energy drinks reduce the depressor effect of ethanol? An experimental study in mice. Physiology and Behavior, 82(5): 841-847.

Friedman L, Weinberger MA, Farber TM, Moreland FM, Peters EL, Gilmore CE and Khan MA (1979). Testicular atrophy and impaired spermatogenesis in rats fed high levels of the methylxanthines caffeine, theobromine, or theophylline. Journal of Environmental Pathology and Toxicology, 2(3): 687-706.

Frungieri M, Gonzalez-Calvar S, Matzkin M, Mayerhofer A and Calandra R (2007). Sources and functions of prostaglandins in the testis: evidence for their relevance in male (in) fertility. Animal Reproduction, 4(3/4): 63-69.

Frungieri MB, Gonzalez-Calvar SI, Parborell F, Albrecht M, Mayerhofer A and Calandra RS (2006). Cyclooxygenase-2 and prostaglandin F2 alpha in Syrian hamster Leydig cells: Inhibitory role on luteinizing hormone/human chorionic gonadotropin-stimulated testosterone production. Endocrinology, 147(9): 4476-4485.

Frungieri MB, Weidinger S, Meineke V, Kohn FM and Mayerhofer A (2002). Proliferative action of mast-cell tryptase is mediated by PAR2, COX2, prostaglandins, and PPARgamma: Possible relevance to human fibrotic disorders. Proceedings of the National Academy of Sciences, 99(23): 15072-15077.

Higgins JP and Babu KM (2013). Caffeine reduces myocardial blood flow during exercise. The American Journal of Medicine, 126(8): 730.e1730.e8.
Higgins JP, Tuttle TD and Higgins CL (2010). Energy beverages: content and safety. In Mayo Clinic Proceedings, 85(11): 1033-1041.

Khayyat L, Sorour J, Al Rawi M and Essawy A (2012). histological, ultrastructural and physiological studies on the effect of different kinds of energy drinks on the liver of Swiss Albino Rat. The Journal of American Science, 8(8): 688-697.

Kleinert H, Pautz A, Linker K and Schwarz PM (2004). Regulation of the expression of inducible nitric oxide synthase. European Journal of Pharmacology, 500(1-3): 255-266.

Meineke V, Frungieri MB, Jessberger B, Vogt H and Mayerhofer A (2000). Human testicular mast cells contain tryptase: increased mast cell number and altered distribution in the testes of infertile men. Fertility and Sterility, 74(2): 239-244.

Moskovitz B, Munichor M and Levin DR (1987). Effect of diclofenac sodium (Voltaren) and prostaglandin E2 on spermatogenesis in mature dogs. European urology, 13(6): 393-396.

Nordt SP, Vilke GM, Clark RF, Lee Cantrell F, Chan TC, Galinato M, Nguyen V and Castillo EM (2012). Energy drink use and adverse effects among emergency department patients. Journal of Community Health, 37(5): 976-981.

Pollard I and Smallshaw J (1988). Male mediated caffeine effects over two generations of rats. Journal of Developmental Physiology, 10(3): 271281.

Reissig CJ, Strain EC and Griffiths RR (2009). Caffeinated energy drinks--a growing problem. Drug and alcohol dependence, 99(1-3): 1-10.

Schell C, Frungieri MB, Albrecht M, Gonzalez-Calvar SI, Kohn FM, Calandra RS and Mayerhofer A (2007). A prostaglandin D2 system in the human testis. Fertility and Sterility, 88(1): 233-236.

Sen CK and Packer L (1996). Antioxidant and redox regulation of gene transcription. The FASEB Journal, 10(7): 709-720.

Stevens A and Wilson I. (1999). The haematoxylins and eosin. In: Bancroft J and Stevens A (Eds.), Theory and Practice of Histological Techqniues, $4^{\text {th }}$ Edition, Churchill Livingstone, London, New York, Toronto: 99-112.

Tanne JH (2012). New York attorney general investigates energy drink makers. BMJ, 345: e6108. https://doi.org/10.1136/bmj.e6108

van den Berg R, Haenen GR, van den Berg $\mathrm{H}$ and Bast A (2001). Transcription factor NF-kappaB as a potential biomarker for oxidative stress. British Journal of Nutrition, 86(S1): S121-S127.

Wang X, Shen CL, Dyson MT, Eimerl S, Orly J, Hutson JC and Stocco DM (2005). Cyclooxygenase-2 regulation of the age-related decline in 
testosterone biosynthesis. Endocrinology, 146(10): 4202-4208.

Wilcox A, Weinberg C and Baird D (1988). Caffeinated beverages and decreased fertility. The Lancet, 332(8626-8627): 1453-1456.

Wolk BJ, Ganetsky M and Babu KM (2012). Toxicity of energy drinks. Current opinion in pediatrics, 24(2): 243-251.

Xie QW, Kashiwabara Y and Nathan C (1994). Role of transcription factor NF-kappa B/Rel in induction of nitric oxide synthase. Journal of Biological Chemistry, 269(7): 4705-4708.

Zeidán-Chuliá F, Gelain DP, Kolling EA, RybarczykFilho JL, Ambrosi P, Terra SR, Pires AS, da Rocha JBT, Behr GA and Moreira JCF (2013). Major components of energy drinks (caffeine, taurine, and guarana) exert cytotoxic effects on human neuronal SH-SY5Y cells by decreasing reactive oxygen species production. Oxidative Medicine and Cellular Longevity, 2013: 22, Article ID 791795. http://dx.doi.org/10.1155/2013/ 791795

Zhao Y, Wang C, Wu J, Wang Y, Zhu W, Zhang Y and Du Z (2013). Choline protects against cardiac hypertrophy induced by increased after-load. International Journal of Biological Sciences, 9(3): 295-302.

Zucconi S, Volpato C, Adinolfi F, Gandini E, Gentile E, Loi A and Fioriti L (2013). Gathering consumption data on specific consumer groups of energy drinks. Supporting Publications 2013; EN394. [190 pp]. Available online at: www.efsa.europa.eu/publications. 